\title{
Case Study - Special Design of Smoke Detection System in a Mental Health Facility in New Zealand
}

\author{
JUDITH SCHULZ, JIM CLARKE and MARTIN FEENEY \\ Holmes Fire \& Safety \\ 39 Market Place, Viaduct Harbour \\ Auckland, New Zealand
}

\begin{abstract}
Specialized buildings such as mental health facilities present unique challenges for fire safety design, as occupants typically should not be evacuated, unless directly threatened by the effects of fire. The New Zealand 'deemed to satisfy' solutions address this with a mandatory minimum requirement for early warning smoke detection and sprinkler suppression systems in buildings with this occupancy, installed in accordance with New Zealand Standards. However, in some instances, the solutions in the Standards are in conflict with clinical requirements to protect patients from (self-) harm. One example is point-type smoke detectors, which should be installed below the ceiling to be compliant with the Standard, but must be located in a protected recess above the ceiling to meet clinical needs.

This case study outlines the performance based design of an aspirated recessed point type smoke detection system in the bedrooms of a secure wing in a mental health facility, operated by one of the largest district health boards in New Zealand. The system was purpose designed to cater for the clinical requirements of the health board. The performance based solution combines the location identification ability of point type analogue addressable detection systems with the unobtrusive installation of aspirating systems.

The system consists of fully recessed proprietary analogue addressable point type smoke detectors that are combined with a small aspirating system. The system was successfully tested in comparison with ceiling mounted point type smoke detectors and was accepted by all stakeholders as a specialized engineered solution giving performance equivalent to that of a Standard compliant system.
\end{abstract}

KEYWORDS: smoke detection, performance based design, clinical occupant safety.

\section{INTRODUCTION}

The New Zealand building regulations have been formulated, in part, to enable and encourage innovative approaches in all areas of design, including fire engineering, with the introduction of the performance based Building Code [1] in 1992. Deemed to satisfy solutions (DTS) are available for fire safety in the form of a compliance document for fire safety for the New Zealand Building Code, C/AS1[2]. The application of these DTS solutions often prove too inflexible to accommodate the special requirements in health care and detention occupancies, so performance based solutions are required to overcome this rigidity.

If solutions are prepared for Building Code compliance which are not in accordance with the DTS document (i.e. using a performance based design approach) then the Fire Service is involved in the building consent process where they act as advisors to the Building Consent Authorities (BCA's). The Fire Service are also required to approve evacuation schemes for these facilities for compliance with the Fire Safety and Evacuation of Buildings Regulations [3].

Where performance based design is used, a qualitative or quantitative comparison between the DTS solution and the proposed performance based solution may be required to demonstrate that the alternative solution achieves a performance level not less than that provided by the DTS solution.

\section{Legislative Environment in New Zealand for Special Care Occupancies}

The deemed to satisfy solutions for special care occupancies, sleeping care (SC) and sleeping detention (SD) are very prescriptive in New Zealand. The following fire safety systems are required as a minimum; automatic sprinkler suppression system, automatic smoke detection system, manual call points, emergency lighting and building hydrants where the building is too large for the Fire Service to reach the furthest point with large bore hoses from the appliance attendance point. Furthermore, where more than 12 patients are 
present in a building, 30 minute fire separations are required to limit the number of exposed patients in any one firecell to no more than 12. Patient areas must also be fire separated from non-patient areas, such as offices. Additional systems are required where buildings have an escape height of more than 10 metres.

The purpose of the automatic fire alarm system in these occupancy types is to notify staff of a fire emergency and allow them to assist patients with the evacuation, rather than to alert the patients to selfevacuate, as acknowledged in the DTS document for Warning Systems [4]. The key performance criteria for the design is therefore the time for staff to be in a position to assist the patient(s) at risk, not the activation time of an alerting device. The DTS solution for fire safety, C/AS1, does not state any requirements for staff to patient ratio, nor whether staff are assumed to be awake at night, nor does it state a preference for conventional or analogue addressable fire detection systems.

\section{Patient Needs and Clinical Requirements of the Client}

One of the largest district health boards in New Zealand owns and operates a number of secure forensic psychiatric hospital units with varying degrees of physical security incorporated in the building design. In these secure units, clinical requirements demand that all of the bedroom areas are specifically designed to minimize the risk of patients harming either themselves or staff. This forms part of the overall philosophy of installed furnishings and fittings, and results in the deletion of anything that could act as a hanging point, or be readily removed for use as a weapon to harm themselves or others. For previous projects, in rooms where high risk patients may be unsupervised for any period of time, all smoke detectors had been located in housings recessed into the ceiling space and covered with a perforated grille to provide a flush ceiling. Sprinkler heads are of an institutional design.

In high risk areas, a proprietary multi-point aspirating smoke detection system was dismissed for two reasons. Firstly, the analyzing device in such an aspirating system typically serves multiple sampling points, which makes exact identification of the room of activation very difficult. In this case study, a proprietary aspirating system would have indicated a zone containing several bedrooms, rather than the exact bedroom of activation. Secondly, the client had had a previous bad experience with this type of system in an earlier project, seemingly due to fluctuating internal air pressures, which resulted in numerous false alarms and the subsequent replacement of the aspirating system with a point type detection system.

The predominant fire risk in buildings of this kind is usually where patients accidentally or deliberately set fire to their rooms using ignition sources associated with cigarette smoking. In these particular units, this risk is considerably reduced as the health board insists on a Smoke Free environment and, as a result, patients are not permitted to smoke in the units, nor are they permitted to carry cigarette lighters or matches on their person. Smoking is only permitted in the outdoor designated areas, with cigarette lighters built into the wall. However, it is readily acknowledged that patients may have concealed lighters on themselves in the past and are likely to do so in the future. The test fire scenarios were selected to reflect this possibility.

\section{Concerns of other Stakeholders}

Although the configuration had been used several times previously, the Fire Service were uncertain about the status of compliance of the recessed detector with the applicable New Zealand Standard NZS 4512:2003 "Fire Detection and Alarm Systems in Buildings" [5], and applied for a formal interpretation by the Alarms and Detection Group of Standards New Zealand. The resultant ruling stated that a point type detector recessed above the plane of the ceiling would not comply with the wording of the Standard, which requires the sensing element to be placed at least $25 \mathrm{~mm}$ below the plane of the ceiling for point type detectors.

The Territorial Authority had no specific concerns, but required that the Fire Service be satisfied before the Code Compliance Certificate would be issued. The fire systems provider raised concerns over the modified location and the chosen sensitivity setting of the recessed detectors.

To address these concerns, an extensive consultation process was undertaken, resulting in the preparation of a special report which outlined the 'Commissioning Test Procedures for Recessed Smoke Detectors'.

The selected design approach followed Clause 101.4 the NZ fire alarm standard [5], that 'Alternative technologies that do not comply with the specific requirements but give equivalent performance are not necessarily prohibited. Appraisal testing will need to demonstrate this to the satisfaction of the relevant 
authority'. A similar incentive is given in the American code, NFPA 5000 "Building Construction and Safety Code (2006)" under Chapter 21, which covers Detention and Correctional Occupancies. It suggests that '[...] other arrangements and positioning of smoke detectors shall be permitted to prevent damage or tampering, or for other purposes. Such arrangements shall be capable of detecting any fire, and the placement of detectors shall be such that the speed of detection is equivalent to that provided by the spacing and arrangements required by the installation standards [..]. Detectors shall be permitted to be located in exhaust ducts from cells, behind grilles, or in other locations.'

The test procedures report was circulated between all stakeholders and was modified to accommodate the request by the Fire Service for increased detail concerning the design and subsequently to include design adjustments after initial unsatisfactory test results. The following sections summarise the details contained in that report, and conclude with the final test results for the aspirated recessed detectors.

\section{PERFORMANCE BASED DESIGN: RECESSED POINT TYPE SMOKE DETECTIORS}

The required performance of the system is to ensure that the time taken for smoke to travel through the grille into the recess and reach the sensing element within the smoke detector is such that the overall response time of the alerting/response system, including staff response to assist the patient at risk, is no worse than that of a standard code compliant system.

The analogue addressable smoke detectors are placed in a ventilated cuboid recessed housing, approximately 3 times the width of the detector and a little higher than the overall detector height, including its base. The recess is located above the main ceiling plane. A grille, mounted flush with the ceiling plane, provides sufficient openings to allow smoke to reach the recessed detector.

The housing has a small opening at the top, around the detector base, to provide venting into the ceiling void and avoid hot air accumulating in the recess.

To compensate for any delay in activation of the recessed detectors, they are programmed with higher sensitivity than required for compliance with NZ alarm standard. The system is also fitted with a small aspirating system to ensure constant air flow past the smoke detector should the HVAC system of the building not operate.

Extensive commissioning testing was required to compare the recessed system with the Standard compliant detector installation.

The following figure outlines the characteristic of the performance based design in comparison to proprietary aspirating detection systems.

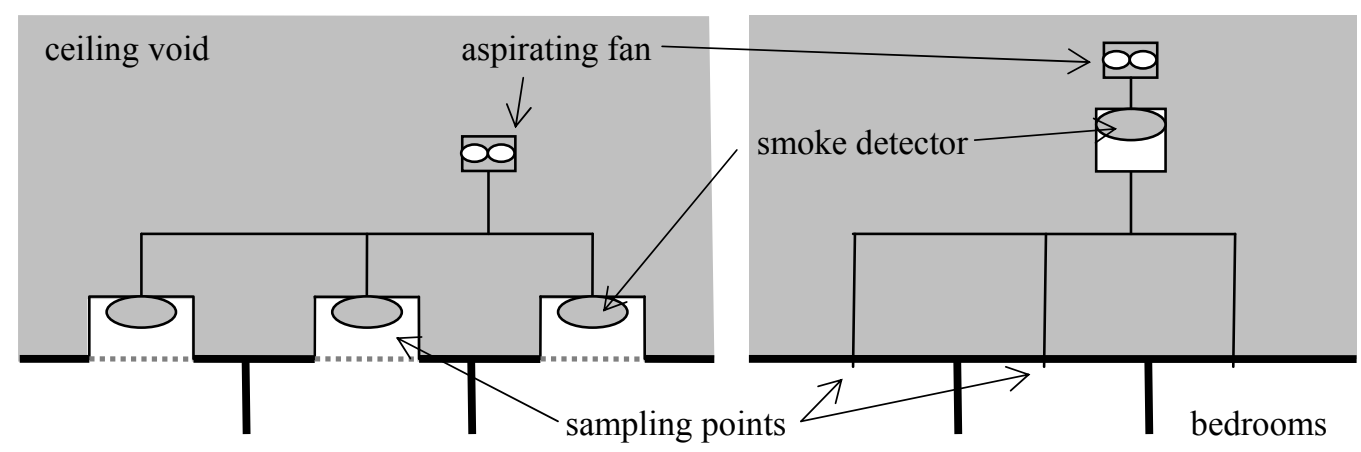

Fig. 1. Performance based recessed system (left) vs. proprietary aspirating system (right).

\section{CHARACTERISTICS OF THE SECURE WING}

This performance based design is closely linked to the building geometry and other building systems, which are listed briefly below. 


\section{Bedrooms}

The bedroom sizes range from around $9 \mathrm{~m}^{2}$ to $11 \mathrm{~m}^{2}$, with some having an ensuite between 3.8 to $4.4 \mathrm{~m}^{2}$. The height of the ceiling in the bedrooms is typically $2.7 \mathrm{~m}$. To minimize smoke spread between rooms and into the corridor, the rooms are constructed with solid walls up to ceiling height, imperforate ceilings (apart from the detector vents) and solid core doors with $25 \mathrm{~mm}$ wide stops. All penetrations are smoke sealed and, apart from a ventilation undercut, the doors have no vents. As shown in the figure below, rooms are located either side of a central corridor, with a nurse base dedicated to the secure wing at one end of the corridor. Doors are not fitted with closers for clinical reasons. The ceiling void is large enough to enable personnel to walk through to carry out maintenance of the building services from above the patient areas.

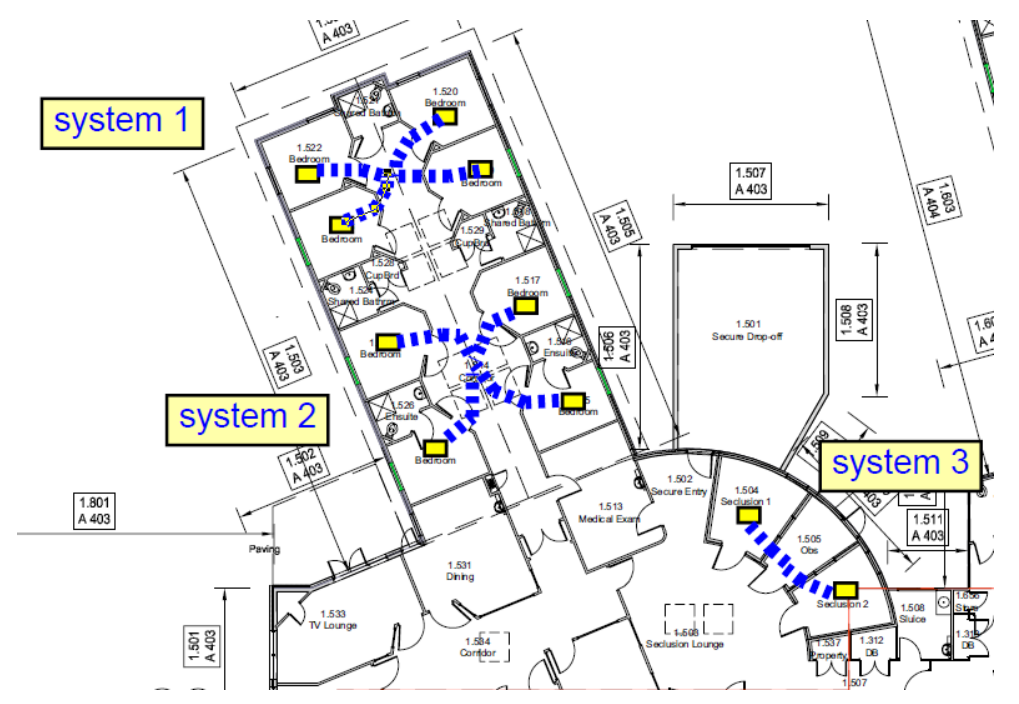

Fig. 2. Bedroom configuration.

\section{Air conditioning}

As windows cannot be opened, the bedrooms are provided with fresh air 24 hours/day, 7 days/week when they are occupied. In the event of a fire alarm, the HVAC system shuts off to minimise smoke spread to other areas. Approximately half of the supplied air is mechanically extracted directly from the bedroom. The bathroom extract system extracts approximately $40 \%$ of the supplied air, with the balance of around $10 \%$ naturally leaking to the corridor e.g. via door undercuts and via the ceiling recess into the ceiling void. Fig. 3 shows the approximate air flows. 


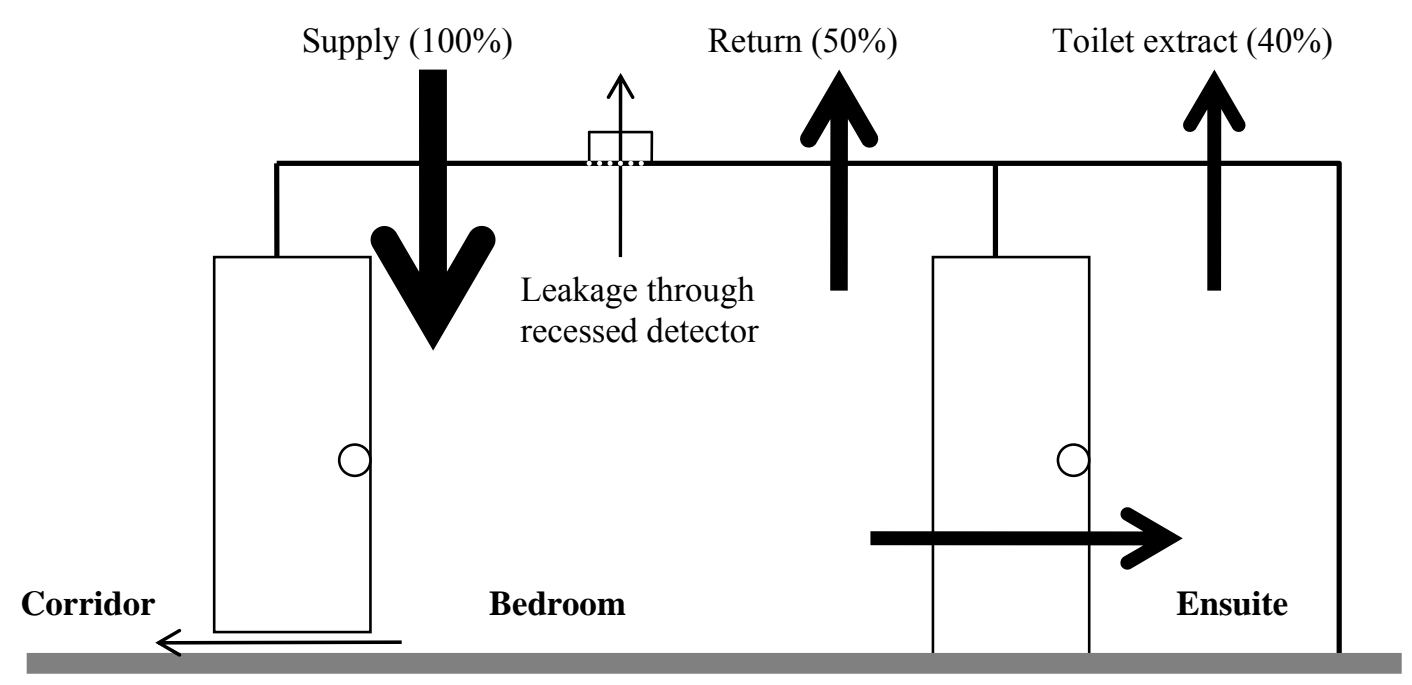

Leakage through undercut

Fig. 3. Schematic of air flow through typical bedroom with ensuite bathroom.

To ensure that there is always airflow through the recessed detector boxes if the HVAC system is not operating, ducted extract fans are mounted in the ceiling void space to achieve low velocity extract, with each fan serving a maximum of four bedrooms. The design provides at least 1 air change per second from each of the recessed detector boxes at a velocity of less than the $5 \mathrm{~m} / \mathrm{s}$ (the detector's maximum air flow velocity in factory tests).

\section{Smoke detector sensitivity}

The entire fire alarm system is analogue addressable, with smoke detectors which allow the sensitivity setting to be modified. The recessed detectors use an algorithm that results in faster response times (often called the 'life safety setting').

\section{Staff numbers}

In the building which is the subject of this case study, the patient areas are staffed 24 hours per day, 7 days a week, with an awake duty during night shift. Staff are formally trained to manage the evacuation of patients at risk as the egress doors in secure areas do not unlock on alarm activation and cannot be opened by patients without staff assistance.

\section{ACCEPTANCE CRITERIA}

The proposed criteria incorporate the importance of staff assisting the patient in their bedroom after alarm activation, not just the alarm activation itself. The criteria therefore make allowance for the benefit of having an analogue addressable alarm system with room-specific detection, over a conventional smoke detection system which only indicates a general zone of activation and then relies on staff to search and identify the exact location of the fire. Such a system would be permissible under the DTS documents.

\section{Importance of Staffing Levels and System Selection}

Based on discussions with the clinical staff, a response time analysis was undertaken to estimate the average time for the first staff member to reach the patient at risk. The ward was assumed to have a maximum of 12 patients in single bedrooms, with 2 or 3 staff on awake duty. For the DTS design, the building was assumed to be fitted with a 'conventional' smoke detection system, which notifies only the 
zone of alarm activation, while the performance based design is fitted with analogue addressable technology with an alphanumeric display at the staff base showing the exact location of the alarm.

The main disadvantage of the conventional system is that the staff only know the zone location, not the exact detector that activated. They are required to search each room in the zone to find the the source of fire.

The following typical response and movement times were advised by the health board, based on test evacuations carried out by staff in similar parts of the hospital:

- Response and travel time of around 30 seconds to reach the first room,

- Travel time of 5 seconds between rooms, and

- Time taken to open a bedroom door, turn on the light, survey the room and confirm whether a fire has started in this room or not, and close the door, of approximately 15 seconds per room.

For a building with an alarm system designed in accordance with the DTS solution, assuming that on average a maximum of 6 of the 12 rooms would need to be checked, the delay after fire alarm alerting until staff can assist a patient in the room of fire origin is around 30 seconds response time to the first room and then between 3 and $6 \times 20$ seconds to find the room of fire origin, i.e. 1.5 minutes for three staff (two searching) or 2.5 minutes for two staff (one searching).

In the proposed alternative design, the average time after fire alarm alerting until one staff member can assist a patient in the room of fire origin is around 30 seconds, as there is no searching required to determine the room of fire origin.

Table 1. Response time analysis of hospital staff.

\begin{tabular}{|l|c|c|}
\hline Scenario & DTS design & $\begin{array}{c}\text { Performance } \\
\text { based design }\end{array}$ \\
\hline $\begin{array}{l}\text { Estimate of average elapsed time following fire alert for two } \\
\text { staff member to assist patient in room of fire origin }\end{array}$ & $1.5 \mathrm{mins}$ & $0.5 \mathrm{mins}$ \\
\hline $\begin{array}{l}\text { Estimate of average elapsed time following fire alert for one } \\
\text { staff members to assist patient in room of fire origin }\end{array}$ & $2.5 \mathrm{mins}$ & $0.5 \mathrm{mins}$ \\
\hline
\end{tabular}

The benefit of an analogue addressable system over a prescriptive conventional system is to provide a quicker staff response by least 60 seconds. The acceptable maximum 'delay' of a recessed detector activating is therefore proposed to be $20 \%$ of the activation time of the surface mounted detector $\mathrm{t}_{\mathrm{act}, \mathrm{c}}$ (equation 1), or 60 seconds (equation 2), whichever is smaller. This margin or 'delay' is used to establish the upper limit of the recessed detector activation time, $\mathrm{t}_{\mathrm{act}, \mathrm{r}}$, in the comparative test.

$\mathrm{t}_{\mathrm{act}, \mathrm{r}} \leq 1.2 \times \mathrm{t}_{\mathrm{act}, \mathrm{c}}$

$\mathrm{t}_{\mathrm{act}, \mathrm{r}} \leq \mathrm{t}_{\mathrm{act}, \mathrm{c}}+60 \mathrm{sec}$

\section{TEST PROCEDURE}

The testing was conducted as part of the commissioning of the systems in the building and was coordinated by the contractor to take place prior to the final fit out of the bedrooms.

\section{Smoke detector comparison}

The detectors used in this facility were model $814 \mathrm{PH}$ combined photoelectric and heat detectors from the Tyco MX range, approved to Australian Standard AS1603.2. The detectors use the MX4428 SMARTSENSE algorithm with the detectors in the recessed housing being set at the faster reacting "alternate" setting. For the commissioning testing, as well as the recessed detector, a second detector was 
mounted on the ceiling next to the grille (see Fig. 4 for photo of test set-up). This detector used the "default" smoke signature algorithm which requires comparison of several features of the activation signal before initiating an alarm. In addition, the sensitivity setting of the ceiling mounted detector was set at an obscuration level that would typically be used for a smoke detector installed in accordance with the relevant New Zealand Standard. The obscuration levels are given in the table below.

Table 2. Sensitivity / Algorithm of smoke detectors (as advised by supplier).

\begin{tabular}{|l|l|}
\hline \multicolumn{1}{|c|}{ Detector location } & \multicolumn{1}{c|}{ Algorithm } \\
\hline Ceiling mounted & Default algorithm with $12 \%$ obscuration $/ \mathrm{m}$ \\
\hline Recessed & Alternate algorithm with $8 \%$ obscuration $/ \mathrm{m}$ \\
\hline
\end{tabular}

The test installation is shown below.

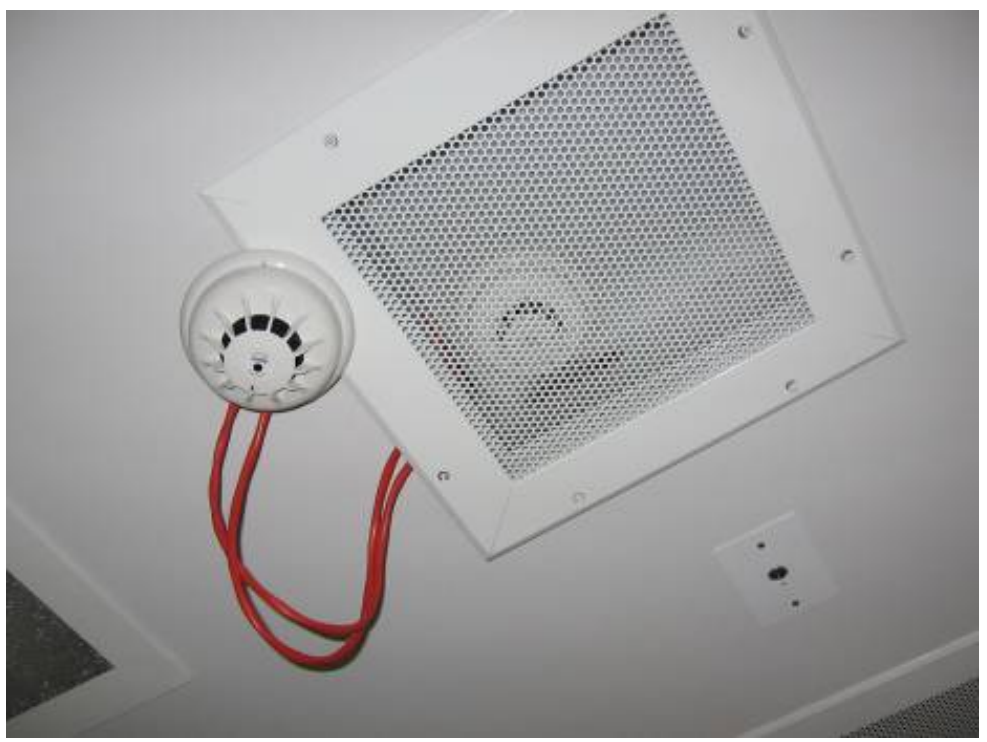

Fig. 4. Recessed detector with surface mounted detector for testing.

\section{Test Scenarios}

The test scenarios were derived from fire scenarios that may be encountered during the life of the building with regard to environmental situations as well as likely fire sources. The tests represented a credible worst case smouldering fire scenario and a rapid growth rate flaming fire that could occur if a patient had access a lighter and a fuel such as paper.

The tests were not intended to establish the suitability of the type of detector itself to react to various smoke signatures. Tests for this purpose are undertaken by the detector manufacturer in accordance with prEN54 or equivalent UL standards and must be passed before the detector can be listed as a NZ Standard compliant detector.

The test fires were located so that they were approximately 2 metres away from the location of the detectors and not positioned directly under the detectors in order to ensure that there was smoke travel across the ceiling before reaching the detectors. 


\section{Smoke Sources}

\section{Smouldering Fire}

The credible worst case fire scenario for life safety in sleeping occupancies is expected to be a low heat release rate smouldering fire where a non-flaming fire creates smoke but insufficient heat is generated to activate a sprinkler and control the fire and smoke production. Significant amounts of smoke could be generated before even smoke detector activation occurs, due to the low buoyancy of the smoke and the extended times for smoke particles to rise and reach the detectors.

For this scenario a piece of corrugated cardboard is rolled tightly and fitted inside a vented metal can. The cardboard was ignited at the bottom with a match to produce a non-flaming smoke source. The smoke produced was only slightly warmer than ambient air temperature to reflect a smoke plume with low buoyancy. Two such sources were used in each test to ensure that there was enough smoke to activate the detectors.

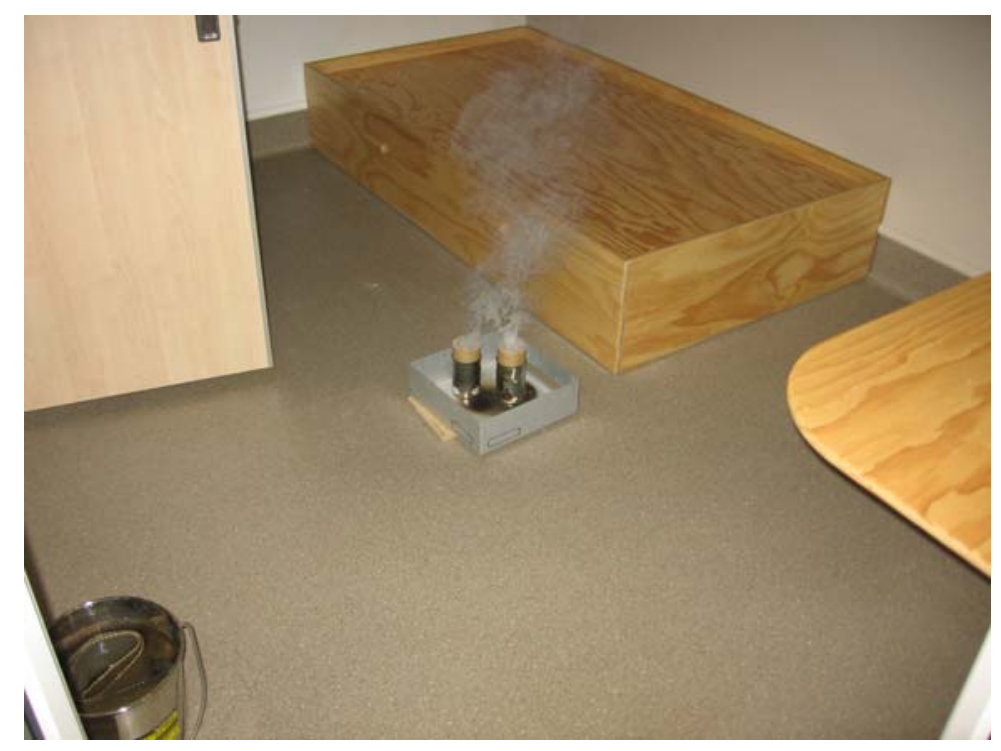

Fig. 5. Smouldering fire with rolled cardboard.

\section{Flaming fire}

To simulate the early stages of a rapidly growing fire, a small fire using 30 crumpled sheets of A4 paper was lit in a metal container, producing a flaming fire with buoyant and relatively clear smoke. The amount of paper limited the resultant flame height to less than 1 metre to protect the room from fire damage. The container was non-combustible and had sufficient penetrations on the sides to allow air to reach the fire (see Fig. 6). 


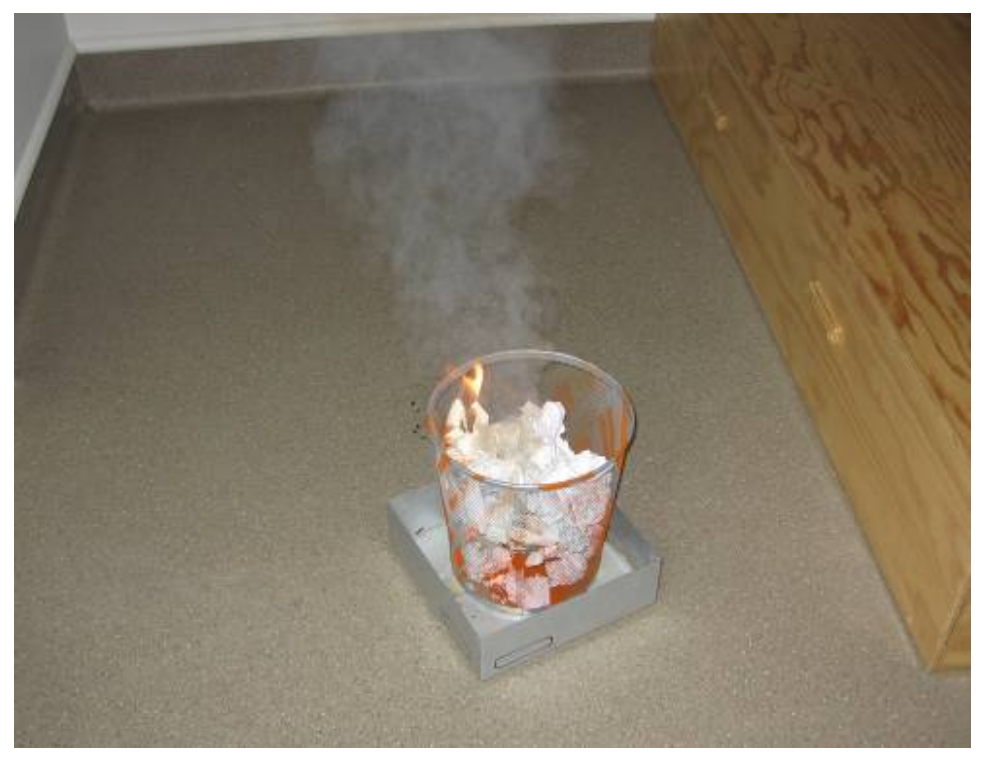

Fig. 6. Flaming fire with paper in bedroom.

\section{Variables in Tests}

Two building parameters were varied during the tests to reflect the way the building is used when occupied:

1. The HVAC system is on (standard system setting when the room is occupied, as it is the only source of fresh air), or the HVAC system is off (to simulate an unexpected system fault or a "copycat" fire after an earlier fire alarm has initiated shutdown of the system).

2. Door to the ensuite is open, or door to the ensuite is closed.

Each scenario was repeated three times, to ensure the results were reliable. A total of 24 tests were done to cover all scenarios. The tests were done alternately in two rooms with slightly different geometry, labelled $\mathrm{A}$ and $\mathrm{B}$, to expedite the commissioning tests.

All stakeholders were invited to the testing.

\section{RESULTS}

Initially, tests were carried out without the aspirating fan in place to determine if, in fact, the recessed detectors were slower to respond than the ceiling mounted ones. Five tests were run with the air conditioning operating as this was considered to be more advantageous for the recessed detectors. In all cases, the ceiling mounted detectors activated first with there being a delay of at least 2 minutes before the recessed detector operated. This did not satisfy the 60 second maximum delay proposed in condition 2 listed above and therefore was not acceptable.

The full commissioning tests were then run with the aspirating fan operating and using the parameters detailed in the previous section. The results of the tests are summarized in the table below. The aspirated recessed detector activated faster than the standard surface mounted detector in all but one scenario (shown in italics), where the recessed detector activated 21 seconds after the surface mounted detector, but still within the permissible acceptance criteria. The recessed system otherwise activated at least 20 seconds faster than the ceiling mounted detector. In some instances the surface mounted detector did not activate within 60 seconds of the recessed detector, or before the test fire burnt out. 
Table 3. Results of commissioning tests - activation times (minutes:seconds).

\begin{tabular}{|c|c|c|c|c|c|c|c|c|}
\hline HVAC & \multicolumn{4}{|c|}{ HVAC on } & \multicolumn{4}{|c|}{ HVAC off } \\
\hline Ensuite & \multicolumn{2}{|c|}{ door closed } & \multicolumn{2}{|l|}{ door open } & \multicolumn{2}{|c|}{ door closed } & \multicolumn{2}{|l|}{ door open } \\
\hline $\begin{array}{l}\text { Detector } \\
\text { location }\end{array}$ & $\begin{array}{l}\text { Recessed } \\
\text { detector }\end{array}$ & $\begin{array}{l}\text { Surface } \\
\text { mounted }\end{array}$ & $\begin{array}{l}\text { Recessed } \\
\text { detector }\end{array}$ & $\begin{array}{l}\text { Surface } \\
\text { mounted }\end{array}$ & $\begin{array}{l}\text { Recessed } \\
\text { detector }\end{array}$ & $\begin{array}{l}\text { Surface } \\
\text { mounted }\end{array}$ & $\begin{array}{l}\text { Recessed } \\
\text { detector }\end{array}$ & $\begin{array}{l}\text { Surface } \\
\text { mounted }\end{array}$ \\
\hline \multirow{3}{*}{$\begin{array}{l}\text { Smouldering } \\
\text { fire }\end{array}$} & $5: 28^{*}$ & $5: 58^{*}$ & $1: 37$ & $2: 06$ & $4: 41$ & d.n.a. & $3: 38^{*}$ & $5: 22 *$ \\
\hline & $4: 34$ & $4: 13$ & $6: 27^{*}$ & $6: 58^{*}$ & $7: 03^{*}$ & $8: 00^{*}$ & $5: 27$ & d.n.a. \\
\hline & $1: 45^{*}$ & $4: 28^{*}$ & $1: 35$ & $1: 55$ & $5: 11$ & d.n.a. & $1: 37^{*}$ & $2: 03^{*}$ \\
\hline \multirow[t]{3}{*}{ Flaming fire } & $0: 52$ & $1: 37$ & $1: 13^{*}$ & d.n.a.* & $1: 24$ & $1: 55$ & $1: 23$ & d.n.a. \\
\hline & $0: 48^{*}$ & d.n.a.* & $2: 19$ & d.n.a. & $1: 27^{*}$ & d.n.a.* & $1: 28^{*}$ & d.n.a.* \\
\hline & $1: 12$ & d.n.a & $1: 07 *$ & d.n.a.* & $1: 28^{*}$ & $2: 14^{*}$ & $1: 28$ & d.n.a. \\
\hline
\end{tabular}

$1: 25=1 \mathrm{~min} 25 \mathrm{sec}$

d.n.a $=$ detector did not activate before fire burnt out or test was stopped

$*=$ tests done in room $\mathrm{B}$

At the end of these tests all parties, including the New Zealand Fire Service and the fire alarm certifier, agreed that the purpose designed aspirating system using recessed detectors reliably provided detection times that were within the parameters that had been agreed in the Fire Engineering Brief consultations.

As a corollary to the acceptance tests, eight subsequent tests were carried out with the recessed detectors set at the same obscuration level and detection algorithm as the ceiling mounted detectors. The client wished to check this configuration in case the higher sensitivity setting was found to cause excessive false alarms. In all of these tests, the surface mounted detector activated first with the delay in the recessed detector activation being just within the $t_{a c t, r} \leq 1.2 \times t_{a c t, c}$ criterion in six tests but exceeding it in two cases. It was agreed with the client that this did not constitute adequate performance and the higher sensitivity setting was retained. In the event, the concern about excessive false alarms has proven to be unwarranted as there have been no activations in the 10 months since the system was commissioned and the unit occupied.

\section{SUMMARY}

The combination of a proprietary analogue addressable point type smoke detection system with a small aspirating system and increased detection sensitivity was found to be an effective solution to provide the location identification ability of the addressable system while maintaining the unobtrusiveness of a proprietary aspirating system. Extensive consultation with the stakeholders was undertaken to establish the test scenarios and acceptance criteria, and over 24 tests showed that the aspirated recessed system provided a performance at least equivalent to that of a fire alarm system compliant with the prescriptive New Zealand Standard.

\section{REFERENCES}

[1] New Zealand Government, (1992) “The Building Regulations 1992”, Wellington, New Zealand.

[2] NZ Department of Building and Housing, (2005) "Compliance Document for New Zealand Building Code for Fire Safety (C/AS1)", Wellington, New Zealand.

[3] New Zealand Government, (2006) "Fire Safety and Evacuation of Buildings Regulations 2006", Wellington, New Zealand.

[4] NZ Department of Building and Housing, (2005) "Compliance Document for New Zealand Building Code for Warning Systems (F7/AS1)", Clause 2.1.2 e), Wellington, New Zealand.

[5] NZS 4512 (2003), "Fire Detection and Alarm Systems in Buildings", Standards New Zealand, Wellington, New Zealand 
[6] NFPA 5000 "Building Construction and Safety Code" (2006), National Fire Protection Association, Quincy, MA, USA, 
